\title{
Lavaipe: Arte Interativa A Partir Da Realidade Virtual
}

\author{
Lavaipe: Interactive Art From Virtual Reality \\ por Maria Cristina da Rosa Fonseca da Silva, Kainan Silvano \\ Fernandes e 0smar Yang
}

RESUMO

0 estudo de caráter teórico-prático aqui apresentado tem como objetivo investigar processos tecnológicos que ampliem a interatividade de pessoas com deficiência com objetos artísticos. A partir de metodologia de cunho qualitativo, a investigação foi iniciada considerando a experiência do Grupo de Pesquisa Educação, Arte e Inclusão com o desenvolvimento de maquetes táteis para públicos especiais em museus de artes. Buscamos propiciar processos de maior interação direta entre público e objeto artístico considerando as contribuições do grupo Sopro Coletivo, formado por pesquisadores, artistas e estudantes de arte, que elaboraram um conjunto de propostas artísticas a fim de possibilitar acessibilidade estética por meio de tecnologias para públicos especiais. Como resultado, obtivemos a criação de quatro objetos artísticos que inicialmente foram pensados separadamente mas que, no amadurecimento do trabalho, foram articulados em forma de circuito estético.

Palavras-chave: Realidade virtual. Realidade aumentada. Arte interativa.

\section{ABSTRACT}

The theoretical-practical study presented here has as objective the investigation of technological processes that enhance the interactivity between persons with impairments and artistic objects. Based on a qualitative methodology, this investigation was started considering the experience of the "Education, Art and Inclusion Research Group" with the development of tactile scale models for special needs public in art museums. We strove to provide a direct interaction between this public and the artistic object considering the contribution made by the group "Sopro Coletivo", composed by researchers, artists and art students who compiled a set of artistic proposals with the goal of enabling aesthetic accessibility by means of technologies oriented for special need public. As a result we had the creation of four artistic objects which were initially conceived separately, but as the work matured they were articulated in the form of a aesthetic circuit.

Keywords: Virtual Reality. Augmented reality. Interactive art. 


\section{Introdução}

0 projeto LAVAIPE tem como objetivo criar e fortalecer o Laboratório Virtual de Arte Interativa para Públicos Especiais. No ano de 2012 foram desenvolvidos estudos em torno do uso da arte como artefato interativo buscando identificar na literatura da área, a criação de artefatos que possibilitassem ampliar a experiência estética de públicos especiais a partir de elementos tecnológicos. Como metodologia utilizamos a abordagem qualitativa e a produção de artefatos com vista à proposição de exposições de arte em que os públicos com deficiência pudessem ampliar suas experiências artísticas. A partir da busca por novas linguagens, as novas tecnologias intituladas realidade aumentada e realidade virtual mostraram-se essenciais para a produção de novas formas de trabaIhar com arte interativa.

Em muitos artefatos desenvolvidos em arte digital são propostos de forma intensa a presença do corpo e do som na experiência artística. Consequentemente, a interação de deficientes visuais pode ocorrer intensamente e explorar uma diversidade de sentidos. As tecnologias de realidade aumentada, que é a integração de informações virtuais e visualizações do mundo presencial e virtual com uma tecnologia de interface avançada entre um usuário e um sistema computacional, são investigadas por artistas e educadores que buscam uma troca maior com públicos especiais. Como resultados deste primeiro ano, desenvolvemos uma exposição intitulada "Favor tocar" e propusemos a criação de novos protótipos desenvolvidos a partir da placa Arduíno, que foram propostos em exposições no ano de 2013.

\section{Apresentação do tema}

Ao construir uma rede entre as linguagens artísticas, surge o fio condutor que pretendemos abordar no presente artigo, que é a interatividade. Domingues (2002, p. 47) aponta que: "os sistemas interativos permitem que os sentidos digitalizados convertam o mundo em unidades binárias, signos de linguagem, que se acoplam em hibridizações com a linguagem dos mundos virtuais interativos". Esse sistema modifica a interação virtual, o modo do indivíduo se relacionar com a tecnologia e constrói novas formas de comunicação. Neste caso, não é só a forma de se comunicar, mas toda a corporeidade que modifica. Giannetti (2006) descreve algumas criações no sentido de promover as primeiras interatividades homem-máquina, marcando o ano de 1962 como a primeira experiência utilizando um capacete simulador de imersão.

No caso da pesquisa com pessoas com deficiência destacamos um aspecto, também ressaltado por Ciannetti (2006), que diz respeito ao domínio ou não da interatividade, com duas situações em relação ao controle das interações: uma primeira tendência onde os indivíduos controlam suas sensações e outra, cujo elemento surpresa permite usufruir da imersão sem controle. Mais uma vez, o entorno virtual participa do processo de fruição e o corpo se constitui como objeto de interação. Melin (2008) relata como os artistas nas décadas de 1960 e 1970, quando surgem as primeiras câmeras, desen- 


\section{Lavaipe: Arte Interativa A Partir Da Realidade Virtual}

volvem suas performances diante delas. A centralidade que permanece nesse contexto é uma ideia do corpo como matéria artística da performance. No caso da pesquisa proposta, o corpo se constitui como matéria da interação entre o cego e a arte.

0 estudo aqui descrito exige, em sua continuidade, um processo criativo e performático que possibilite a proposição de experiências estéticas pelo grupo de pesquisa que sejam fruídas pelos cegos de modo tecnológico. Para tanto, foi constituído um coletivo de artistas intitulado "Sopro Coletivo". Uma das questões iniciais que nos colocamos como objeto de estudo foi se a experimentação do cego no ambiente artístico criado prescindirá de mediação educativa, ou ainda se ela acontecerá somente no processo do laboratório e não nas instituições culturais; ou ao contrário, se não ocorrerá no laboratório e sim na exposição. Ao longo do desenvolvimento do projeto, observamos que as duas possibilidades foram possíveis.

Bourdieu (2007) desenvolveu uma pesquisa em 1966 nos museus da Europa (Espanha, França, Polônia e Grécia), a qual identificou que quanto maior a instrução do público, maior a frequência nos espaços expositivos. Esse acesso reduzido para não letrados nos faz pensar a mediação educativa nos espaços culturais como estratégia de aproximação do público com a arte contemporânea, pois mobiliza atitudes diferenciadas que adentram o campo educativo. 0 acesso das classes populares, dos públicos com deficiência e idosos, entre outros públicos afastados do acesso aos códigos da arte, nos desafia a propor estratégias que aproximem os participantes dos processos de criação nas exposições acessíveis. A mediação educativa pensada numa perspectiva inclusiva e emancipatória pode propor uma aproximação com os públicos diferenciados desenvolvendo processos críticos de diálogo entre as diferentes experiências do público em geral com o sistema das artes.

Autoras como Coutinho (2009) e Koneski (2008) apresentam argumentos que nos auxiliam a qualificar a ação educativa. Segundo Coutinho (2009, p. 4): “[...] penso que é urgente em nosso contexto brasileiro refletir sobre as ações educativas que tenham por finalidade favorecer aproximações com a arte e a cultura, sobretudo aquelas que têm como foco os sujeitos que historicamente foram apartados destes conhecimentos". Já Koneski (2008, p. 33) questiona essa possibilidade de comunicabilidade diante da arte contemporânea. Segundo a autora: "Podemos pensar na possibilidade de estarmos diante de outra estrutura de conhecimento que não se reduz ao prender do compreender (a uma intencionalidade), em que o fracasso da comunicabilidade, por ser ético é o que nos salva". Ao referir-se ao prender do compreender, nos faz intuir que sua abordagem se refere aos discursos prontos, as verdades institucionalizadas e sacralizadas sobre a arte contemporânea que, segundo a autora, não apresentam a mesma maneira de se colocar diante do público se comparada a arte produzida em outros tempos.

A fraqueza da comunicabilidade é o fato que permite à obra ser fundante de sua própria hermeticidade a fim de que os diversos "eus" (críticos, instituições, historiadores, estetas, enfim todos os que se reservam o direito de inferir sobre a arte) não instaurem na obra a comunicabilidade que the convém. Isso salva a arte de enquadrar-se dentro de regras de conduta, que ditem como ela deve se "comportar" para ser arte. (KONESKI, 2008, p. 33). 


\section{Lavaipe: Arte Interativa A Partir Da Realidade Virtual}

Um conjunto de indagações do ponto de vista da produção e da formação estética se enfileira no cenário dessa proposta e muitas perguntas se colocam na ordem do dia. Como ocorre a interação virtual do cego com a arte? Qual o papel do som nesse contexto? Como o corpo interfere nesse contexto? Que sensações as propostas interativas acarretam ao cego? Quais as diferenças entre os ambientes virtuais produzidos em laboratório e os ambientes imersivos nos espaços expositivos? Que mudanças ocorrem no cenário da arte contemporânea em direção as relações entre arte e tecnologia? Que estética permeia a arte digital?

Arantes (2005) resgata o movimento de transformação ocorrido no cenário das artes, inclusive apontado na atualidade do pensamento de Walter Benjamin em relação à reprodutibilidade técnica da obra de arte. Da mesma forma, a autora resgata os princípios dessa estética digital e aponta duas direções: a dos artistas que se utilizam da mídia computacional para desenvolvimento de suas produções artísticas e a dos artistas que utilizam os recursos multimídia para construir uma interatividade entre artista e público, ou mesmo entre público e público, ou ainda público e máquina. Nosso objeto de estudo está circunscrito ao cenário das interações entre a pessoa cega e a arte, tendo como elemento de relação as possibilidades tecnológicas de produzir um pensamento estético a partir do envolvimento corporal do cego. Acreditamos que essa experiência auxiliará a pessoa cega a compreender o universo da arte contemporânea e estabelecer com ela uma relação estética, ampliando seu modo de perceber o mundo.

Considerando as mudanças na política de inclusão brasileira também do ponto de vista do desenvolvimento da cultura, da ciência e da tecnologia e suas imbricações com a inserção de novos segmentos no mercado de trabalho, as políticas públicas do país têm criado redes de apoio para projetos que envolvam públicos especiais. Desse modo, o LAVAIPE, Laboratório Virtual de Arte Interativa para Públicos Especiais, criado pelo grupo de pesquisa Educação, Arte e Inclusão, formado por profissionais, técnicos e estudantes de diversos centros da UDESC, busca investigar as possibilidades de espaços de acessibilidade para públicos especiais no âmbito da educação e da arte. Neste contexto, pretendemos ao longo do estudo ampliar a estruturação e a consolidação do LAVAIPE a fim de impulsionar a criação de artefatos tecnológicos que possibilitem a interação estética.

De acordo com Bahia (2008), cresce em nosso contexto a existência de museus virtuais de games que utilizam a arte como conteúdo, ou mesmo como veículo de ludicidade, de possibilidades de cinema, áudio e vídeo com grande interatividade. Os consoles de jogos eletrônicos atuais, como o Nintendo Wii, por exemplo, também ampliam seus potenciais de interatividade e envolvem adultos e crianças num conceito diferenciado de jogo. A interatividade não se restringe à escolha de direções e botões para clicar; todo o corpo se envolve nessa experiência. Por outro lado, é raro que essas experiências de interação envolvam e sejam acessíveis para públicos especiais. Apresentamos nesse artigo fragmentos iniciais da pesquisa desenvolvida entre os anos de 2011 e 2012, bem como a estrutura criada para as exposições de 2013. 


\section{Lavaipe: Arte Interativa A Partir Da Realidade Virtual}

\section{A arte como proposição interativa}

As novas tecnologias fazem parte do cotidiano das pessoas. Tanto nas escolas como no cotidiano amplia-se o acesso aos avanços tecnológicos. A interatividade está por todos os lados, no telefone celular, que também possui ferramentas de conexão à internet, nos vídeo games, laptops, palmtops, telas sensíveis ao toque e tantas outras ferramentas que surgem como novidade anualmente.

Pesquisadores das artes também vêm tornando real a comunicação entre as artes visuais e a tecnologia. No estudo de Bambozzi, Bastos e Minelli (2011) vemos a organização de um trabalho de vários pesquisadores em mediações, tecnologia e espaço público que percorrem de maneira cronológica os avanços da tecnologia e suas diversas aplicações nas artes, principalmente a mídia em espaços públicos.

A interação se caracteriza como projeção de imagens captadas com webcams e sensores digitais que, pressionados, fornecem uma resposta ao público visitante; luzes e cores interagindo com sons emitidos pelo computador, efeitos luminosos, poemas digitais e muito mais. É importante a participação do público nas obras interativas porque a resposta ao estímulo torna completa a obra. A interação é possível quando, além da arte visual, associamos também à programação. Com a placa Arduíno trabalhamos a linguagem Processing e animações que podem ser elaborados com softwares que existem no mercado. Entre eles destacamos HTML5, Flash e 3dSmax.

Janota (2003), por meio do livro FLASH Actionscript MX, mostra aplicações diretas e exemplos que dão a liberdade de recriar situações que podem ser aproveitadas dentro do processo criativo de um jogo lúdico e interativo. Barata e Santos (2010) nos permite adentrar no mundo imaginativo da terceira dimensão e, assim como a animação em Flash, em 3D MAX pode-se elaborar o protótipo da experiência do jogo interativo para públicos especiais simulando os efeitos e controles a serem apresentados futuramente no produto final, a obra em si.

Assim como Barata e Santos (2010), Borenstein (2012) também nos faz imergir no mundo da programação na linguagem Processing permitindo que criemos modelos digitais em $3 \mathrm{D}$ que podem ser manipulados ao comando de gestos e mensagens de voz. Sempre é bom lembrar que podemos criar um protótipo em tamanho menor onde podemos trabalhar com circuitos pequenos e placas que permitem testar os equipamentos antes de serem elaborados em larga escala. Monk (2010), com seus exemplos de circuitos eletrônicos, nos aponta ideias e sugestões que sugerem soluções a possíveis eventualidades.

Assim, percebemos que estudos vêm sendo realizadas com a placa Arduino no contexto do imbricamento entre artes e tecnologias que visam, segundo Dênis de Moraes (2010), buscar inovação e desenvolvimento e novas perspectivas das tecnologias de comunicação. Na Arte de Game Design de Schell (2011) encontramos ideias de prototipagem e princípios para a construção de jogos interativos. São estes jogos interativos que proporcionam a imersão do público na arte permitindo que a obra se complete.

Guimarães (2008), na comunicação tecnoestética nas mídias, nos introduz a estratégias e técnicas em relação ao imaginário e nos conduz por vários temas que estão ligados 


\section{Lavaipe: Arte Interativa A Partir Da Realidade Virtual}

às artes e à tecnologia. Hoje, a preocupação do artista é interagir com seu público. Muitas vezes é o próprio público que completa a obra. Nunes (2010) revela uma série de ferramentas possíveis desde os tempos primórdios da era da computação onde percebemos a web, a hegemonia cyborg, Wikipédia, freakpedia. Igualmente, a arte de cunho sociológico e os artistas aproveitam esses recursos com o intuito de divulgar seus trabalhos artísticos e interagir com seu público. Estas produções-tarefas podem ser enviadas ou postadas para um público que pode ter acesso a elas por meio de equipamentos móveis.

A emissão de ondas pelos equipamentos móveis nos remete ao sistema wireless e encontramos em Faludi (2010) um guia que nos permite encontrar soluções para elaborar redes de sensores sem fio e dispositivos inteligentes que nos permitam alcançar a interação da obra com o público por meio de toques que transmitam à placa Arduíno a mensagem esperada para que a obra se complete.

Consideramos que as experiências de um conjunto de artistas que abordam o tema da arte e tecnologia podem contribuir para a ampliação da experiência estética de pessoas com deficiência. Uma acessibilidade na arte pode encontrar caminhos a partir dos artefatos tecnológicos construídos de modo interativo articulando múltiplas linguagens das artes e sua multissensorialidade.

\section{Realidade Virtual e Realidade Aumentada}

Durante a pesquisa estabelecida no projeto, ficou claro que dois conceitos são cada vez mais pertinentes e relevantes ao universo computacional e tecnológico. Os conceitos de realidade virtual e realidade aumentada. Ambas estão estreitamente ligadas desde suas criações.

Como Kirner e Siscoutto (2007) discorrem sobre a realidade virtual surgiu na década de 60, projetada por ScketchPad, de Ivan Sutherland, no ano de 1963, mas só foi surgir como algo inovador no final da década de 80, quando as tecnologias computacionais estavam mais avançadas e interativas. Entretanto, a realidade virtual sempre foi mais complexa para execução por necessitar de diversos equipamentos para ocorrer, o que popularmente pode ser chamado como imersão virtual.

A partir da realidade virtual na década de 90, surge a realidade aumentada, que é a sobreposição de figuras e ambientes virtuais com o ambiente físico, usando dispositivos computacionais tecnológicos. Mesmo com maior facilidade para execução, somente nos anos 2000, em virtude de melhorias nas técnicas computacionais e aparelhos com melhor custo e benefício, as projeções de realidade aumentada ficariam mais acessíveis (KIRNER; SISCOUTTO, 2007).

Tanto a realidade virtual quanto a aumentada proporcionam uma interação entre ambiente virtual e físico, tornando-se assim uma linguagem diferente para trabalhar no campo da arte. Como Galvão descreve: 


\section{Lavaipe: Arte Interativa A Partir Da Realidade Virtual}

A nova configuração imposta pela estética tecnológico-digital altera o sentido tradi-
cional que a teoria crítica conferiu à técnica e, por extensão, à tecnologia e à relação
entre arte e técnica ou entre arte e tecnologia. A arte tecnológico-digital opera no me-
canismo de, pelos dispositivos tecnológicos, negar uma linguagem pré-formada. Nes-
se processo, o indivíduo (interator/autor) é levado a uma situação "sem linguagem",
na qual ele opera a desmaterialização da própria linguagem (GALVÃo, 2008, p.16).

A partir dessa situação de nova linguagem, acontecem os primeiros experimentos entre autor, obra e novas tecnologias. Souza e Silva (2004) cita a instalação Telematic Dreaming, do artista Paul Sermon, no início dos anos 90, como um dos embriões da arte usando os artifícios da realidade aumentada e virtual como linguagem. 0 artista, por meio de realidade aumentada, criou uma "cama virtual" que poderia ser compartilhada por diferentes pessoas em diferentes lugares. Haviam duas camas, e a imagem do indivíduo ausente era projetada na cama fisicamente presente. Uma cama localizada em um espaço escuro, enquanto a outra em um ambiente claro. A pessoa era filmada deitada na segunda cama enquanto uma câmera enviava simultaneamente a imagem para o outro ambiente, projetando a sua imagem na cama situada no espaço escuro. Ainda no quarto escuro, mais uma câmera capturava a imagem de outra pessoa na cama e a enviava para diversos monitores da instalação. Ao se olhar para as imagens dos monitores ocorria a ilusão de duas pessoas estarem compartilhando o mesmo espaço.

Inúmeros artistas trabalham com o conceito de realidade virtual, não somente pela possibilidade de uma nova tecnologia e por simples curiosidade ao novo; cada vez mais a arte interativa pensa e trabalha em novas formas para trazer o espectador para dentro não somente da experiência da obra, mas principalmente para a composição desta. Como detalha Arantes:

Nada aqui existe para ser contemplado no sentido tradicional da manifestação artística, já que o corpo do público é chamado a instalar-se na obra. Segundo esse conceito, só podemos chamar de "obra" a totalidade resultante da relação entre a coisa instalada, o espaço constituído por sua instalação e o próprio espectador, que não se encontra fisicamente fora da obra, a contemplá-la como realidade exterior, mas ao contrário, a "habita" (ARANTES, 2005, p.119).

Com os estudos sobre a placa Arduíno, realidade virtual e aumentada, e pensando em formas de trabalhar com públicos especiais em meios interativos, em novembro e dezembro de 2011 a pesquisadora e artista Adriane Kirst, junto com o Grupo de Pesquisa Educação Arte e Inclusão, desenvolveu a exposição "Favor tocar" uma instalação sonora que foi montada na Galeria de Artes Martinho de Haro, propondo a interação entre público e obra.

\section{A exposição "Favor tocar" e os artefatos inclusivos}

A instalação foi pensada através da tecnologia kinect, um dispositivo que se move 


\section{Lavaipe: Arte Interativa A Partir Da Realidade Virtual}

sensorialmente, criado pela Microsoft para o conjunto de ferramentas que compõe 0 vídeogame Xbox 360. 0 kinect permite que a pessoa interaja com o jogo sem 0 uso de dispositivos controladores, o que comanda e interage com o console são os movimentos e sons emitidos pelo jogador, que se tornam a interface do jogo.

A proposta da instalação, o uso do kinect por meio dos movimentos dos braços do espectador iria controlar a intensidade, o volume e o ritmo do som que sairia da obra. 0 som escolhido foi do teremim, um dos instrumentos musicais eletrônicos mais antigos, que não precisa de contato físico para ser tocado. Tradicionalmente, este instrumento opera através do princípio da produção de efeito de um oscilador audivel de frequência radiofônica, composto por caixa com duas antenas externas, sendo que uma controla a altura e a outra, o volume, ao redor das quais o músico movimenta suas mãos para produzir som, sem tocar em nada. Já o teremim na instalação "Favor tocar", resultou da combinação entre uma rede de computador, uma caixa de som e um kinect.

0 som emitido pelo teremim não é comum, talvez um tanto assombroso para quem nunca manipulou um instrumento. No caso da instalação, caberia encarar o desafio proposto pela artista, em pedido quase autoritário, colocando o espectador no comando da ação. 0 público que talvez não seja músico, ou mesmo nunca pensou em tocar um instrumento e geralmente não se vê parte de maneira tão completa e profunda em uma obra de arte, é convidado a fazer algo que usualmente não faria. Criando uma experiência, um momento onde os sons se propagam por meio de uma tecnologia descomplicada e direta, fazendo a ponte entre o sentir e o mover.

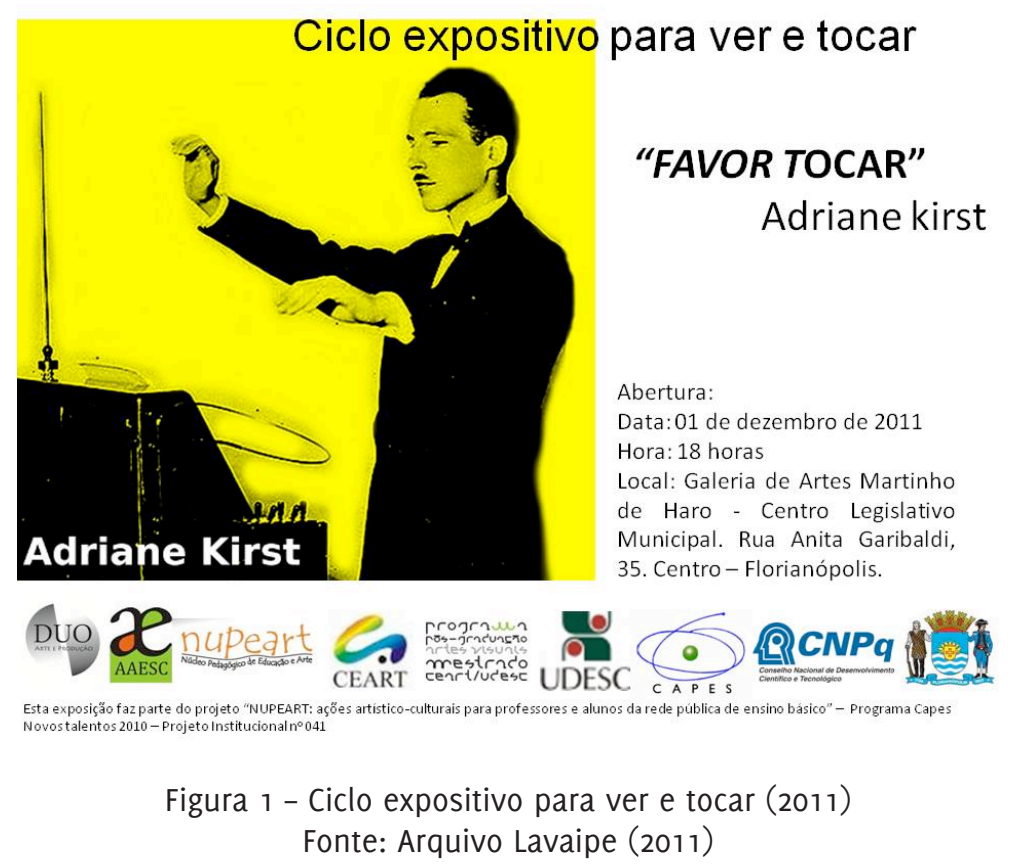

Artistas como Júlio Lúcio, que fazem uso de equipamentos como a placa Arduíno e sensores de movimento, possuem obras com características que necessitam a "perda" de um ou mais sentidos do espectador para se tornarem relevantes a outros sentidos como, por exemplo, a obra purpuryBot onde três bacias de purpurina com diferentes 


\section{Lavaipe: Arte Interativa A Partir Da Realidade Virtual}

aromas ficam em frente a um letreiro escrito "Feche os olhos", a medida em que 0 espectador se aproxima da instalação, um sensor de presença comunica sonoramente para o visitante fechar os olhos e, em seguida, um ventilador em baixa velocidade assopra a purpurina na face da pessoa. 0 fechar dos olhos não é somente uma simples necessidade de segurança e sim uma maneira de aguçar outros sentidos do espectador, como o olfato e o tato.

A instalação "Favor tocar" não necessitou dos olhos fechados por parte do espectador para funcionar de forma completa. 0 sentido visual não traz relevância alguma para a obra, onde os movimentos e a audição eram parte da ação. Entretanto, no campo das Artes Visuais, não somente a problemática da multissensorialidade está no contato presente com as obras, mas também historicamente.

Por mais que a denominação seja Artes Visuais, atualmente o campo proporciona que as obras de arte sejam percebidas por meio de outros canais perceptivos que vão além da visão, muitas vezes convidando o espectador a interagir com a obra. A forte presença da pintura e da escultura dentro de toda a história da arte e dos espaços expositivos contribui para um estranhamento do público em relação aos novos suportes. Observa-se a existência de um senso comum que valoriza as obras "tradicionais de arte" e marginaliza os trabalhos que investem nos demais tipos de percepção por parte do grande público. Neste contexto, emergem diversas problemáticas que dizem respeito à formação estética do público que não acompanhou a evolução das vanguardas artísticas.

Por meio de propostas de arte contemporânea e investigação, a exposição "Favor tocar" buscou uma relação entre os sentidos e a computação, de maneira que as fronteiras entre a tecnologia, a vida e a arte se aproximem interativamente. Arantes mostra que 0 corpo se torna o fator mais relevante da obra:

Nas instalações que lidam com recursos digitais, os sinais enviados pelo corpo do interator - sopro, tato, deslocamento corporal, voz, etc. - são recebidos pelo computador e transformados, em tempo real, em paradigmas computacionais. Nesses casos, o corpo é o motor da obra, já que é a partir dos sinais enviados pelo corpo do interator que a obra pode se manifestar. (ARANTES, 2005, p. 121)

0 título da exposição faz referência aos espaços onde é possível encontrar placas escritas com a frase "favor não tocar". Aqui, ao contrário, a obra necessita ser tocada para existir. Essa possibilidade de tocar a obra é a ferramenta que possibilita uma maior interação com o público cego.

\section{Novos Artefatos Tecnológicos}

A primeira etapa do trabalho de criação foi fundamentar o estudo a partir da experiência de outros artistas que desenvolveram projetos em arte e tecnologia - sobre este tema ver Poffo, Guglielmi e Yang (2012). Com base nos estudos conceituais, os participantes do Sopro Coletivo iniciaram a produção de diferentes objetos estéticos interativos que 


\section{Lavaipe: Arte Interativa A Partir Da Realidade Virtual}

teriam como objetivo ampliar as possibilidades de estimular a multissensorialidade estética dos públicos especiais.

Com o término dos projetos individuais, o coletivo observou a necessidade de maior integração entre os trabalhos e essa nova necessidade criou alguns temas complexos para resolução. Um primeiro deles foi propor a criação de um tablado que servisse de elemento de ligação entre os objetos, que pudesse igualmente criar um espaço de caminhada e sustentar a parte elétrica e eletrônica.

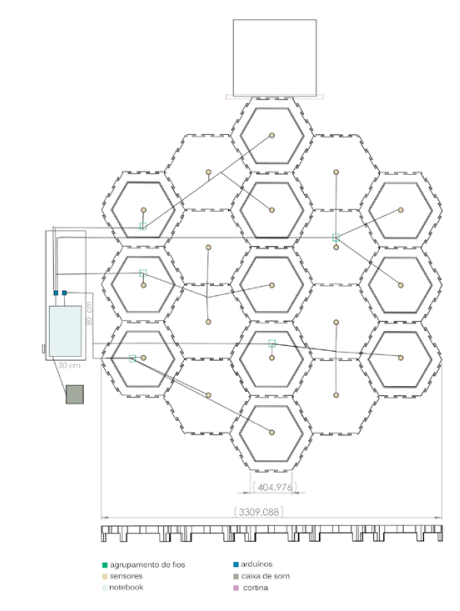

Figura 2 - Projeto Tablado

Fonte: Arquivo Lavaipe (2012/2013)

A possibilidade de caminhar sobre as placas em forma de hexágono acionam os sensores que, lidos por uma placa Arduíno em conjunto com um microcomputador central, criam um som e uma imagem específicos. 0 tablado possibilita também trajetos múltiplos com programações diferenciadas a cada parte do percurso.

Após a livre exploração do tablado, o público tem acesso a um conjunto de imagens e sons que relatam fragmentos de sonhos que se relacionam com o som no percurso do tablado e que, ao chegar no casulo, a parte final em forma de quadrado, são projetados em forma de vídeo. Nesta parte final há também um espaço de aconchego intitulado casulo em que o público acessa texturas diferenciadas que ampliam a ideia de aconchego. Todo o percurso é marcado por texturas diferenciadas que são sentidas por meio do contato dos pés com os hexágonos. 0 ambiente é mantido em penumbra para diminuir a dependência do público aos estímulos visuais, mas o percurso é claramente marcado pelos intervalos entre as placas hexagonais.

Na parte de fora há uma jaqueta sensorial que produz interações a partir dos movimentos realizados com os braços e pernas. Os tabletes disponíveis na exposição ampliam as possibilidades de acesso às instruções que favorecem a acessibilidade dos objetos artísticos. Nessa condição, o próprio público pode iniciar e navegar nas instruções para não depender dos sensores. Disponibilizamos uma programação para que, ao apertar 


\section{Lavaipe: Arte Interativa A Partir Da Realidade Virtual}

o play, iniciar-se-á o áudio para cegos e, para surdos e um vídeo em linguagem libras ou texto.

As possibilidades de inserção de cheiros, sensações e situações artificiais contribuem para a ampliação do acesso às experiências estéticas. Cabe ressaltar que não existe, no caso dos públicos especiais, uma experiência igual para todos. Cada deficiência exige um tipo de acessibilidade, fato que possibilita um conjunto distinto de interações estéticas.

\section{Aspectos Técnicos do projeto Sensever}

A realização física do projeto foi concebida de modo a utilizar recursos disponíveis ou de baixo custo, demonstrando que os avanços tecnológicos tornaram viáveis a utilização de recursos eletrônicos e computacionais que seriam proibitivos apenas alguns anos atrás. Na base do sistema está o microcontrolador open source de baixo custo Arduino, que será utilizado em duas versões, Arduino Nano e Arduino Lilypad.

Os sensores a serem instalados nas placas hexagonais devem ser sensíveis à pressão para detectarem a presença da pessoa e a sua localização. Para tal foi escolhido o sensor piezoelétrico por ser de baixo custo e boa confiabilidade:

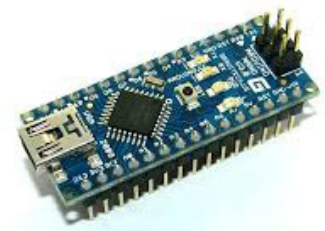

Figure 1 - Nano Arduíno

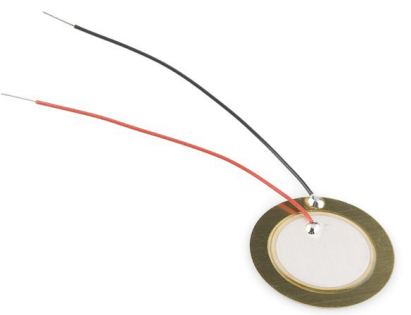

Figure 2 Sensor

Instalamos um sensor para cada placa hexagonal, permitindo a localização do usuário (será permitido apenas um usuário de cada vez no percurso). Os sinais originados pelos sensores serão detectados pelos Arduinos e comunicados ao microcomputador central onde um programa escrito no ambiente de processamento gráfico opensource Processing escolherá os fragmentos de sonhos que irão compor o sonho na sua totalidade. Um algoritmo aleatório programado no software irá garantir que a mesma placa hexagonal acionada por outro usuário possa gerar um fragmento de sonho diferente. Sendo assim cada sonho será único na sua composição final. 


\section{Lavaipe: Arte Interativa A Partir Da Realidade Virtual}

\section{Considerações finais}

Com a pesquisa elaborada a partir de uma série de novos e recentes conceitos que vêm sendo trabalhados há alguns anos no meio tecnológico, mas um tanto quanto recentes no campo da arte, deixa-se como saldo positivo a experiência da exposição "Favor tocar" e da exposição "Sensever". Certamente que ainda há muitos problemas de acessibilidade e contato de públicos especiais com as obras de arte contemporâneas. Entretanto, com iniciativas e projetos elaborados voltados para trabalhar não mais somente artes como um meio visual de comunicação e relacionamento e o envolvimento não ser pensado apenas como artista-obra-espectador, e sim uma contribuição total e em um conjunto de artista e espectador que resultaria na obra. A imersão sensorial da realidade virtual possibilita uma experiência mais rica do que um estímulo de apenas um sentido, e isto é válido também para públicos que apresentam alguma deficiência sensorial. 0 que queremos demonstrar também é que a tecnologia para realizar esta imersão já está disponível e acessível, propiciando um campo de pesquisa ainda relativamente inexplorado, mas cujo potencial já nos é possível vislumbrar.

Como visto nos itens pautados anteriormente, há muito espaço para o corpo e o espectador trabalharem a favor e junto à obra, mesmo com o problema histórico da relutância a novas linguagens para trabalhar arte. 0 que poderia ser chamado de tradicionalismo se transforma em uma parcela de público que talvez ainda não perceba que as tecnologias digitais já fazem parte diretamente do campo das artes.

Em nível de estudo, a placa Arduíno e as realidades virtual e aumentada são, com certeza, novas proposições a serem estudadas e pensadas de como podem continuar trabalhando junto do meio artístico e em favor deste. Novas pesquisas em um meio certamente promissor deverão ser cada vez mais buscadas. 


\section{Lavaipe: Arte Interativa A Partir Da Realidade Virtual}

\section{Referências Bibliográficas}

> ARANTES, Priscila Almeida Cunha. @rte e mídia: perspectiva da estética digital. São Paulo: Senac São Paulo, 2005.

> BAHIA, Ana Beatriz. Jogando arte na web: educação em museus virtuais. Florianópolis, 2008. 401 p. Tese (Doutorado em Educação) - Universidade Federal de Santa Catarina/UFSC, Florianópolis, 2008.

> BAMBOZZI, Lucas; BASTOS, Marcus; MINELLI, Rodrigo. Mediações, Tecnologia e Espaço Público. São Paulo: CONRAD, 2011.

> BARATA, João; SANTOS, João. 3Ds MAX Curso Completo. Rio de Janeiro: Autodesk, 2010. $>$ BOURDIEU, Pierre; DARBEL, Alain. 0 amor pela arte: os museus de arte na Europa e seu público. São Paulo: Editora da USP, Porto Alegre: Zouke, 2007.

$>$ BORENSTEIN, Greg. Making Things See: 3D vision with Kinect, Processing, Arduino, and MakerBot. USA: Editora BEIJING, 2012.

> COUTINHO, Rejane. Questões sobre a formação de mediadores culturais. Encontro da Associação Nacional de Pesquisadores em Artes Plásticas, 18., 2009, Salvador. Anais... Salvador: ANPAP, 2009. Disponível em: < http://www.anpap.org.br/anais/2009/pdf/ceav/ rejane_galvao_coutinho.pdf >. Acesso em: 31 out. 2013.

$>$ MORAES, Dênis de. Mutaciones de lo visible: comunicación y procesos culturales en la era digital. Buenos Aires: Paidós, 2010.

> YANG, Osmar, GUGLIELMI, Rebeca, MACHADO, Samira, Poffo. A construção de objetos artísticos inclusivos e interativos através do projeto LAVAIPE. In. REVISTA EDUCAÇÃO, ARTE E INCLUSÃO. Volume 6, número 2, Ano 2012. p 01-18.

> DOMINGUES, D. Criação e interatividade na CIBERARTE. São Paulo: Experimentos, 2002.

> FALUDI, Robert. Building Wireless Sensor Networks: with ZigBee, XBee, Arduino, and Processing. USA: Farnham, 2010.

> GALVÃO, Edilamar. Arte e tecnologia: diferença e invenção. Revista FACOM, n. 19, v. 1, São Paulo, 2008. Disponível em: 〈http://www.faap.br/revista_faap/revista_facom/ facom_19/edilamar.pdf >. Acesso em: 3 set. 2013.

> GIANNETTI, Claudia. Estética digital: sintonia da arte, a ciência e a tecnologia. Belo Horizonte: C/Arte, 2006.

> GUIMARÃES, Denise. Comunicação Tecnoestética nas Mídias Audiovisuais. Rio Grande do Sul: SULINA, 2008.

> JANOTA, Dauton. FLASH Actionscript MX. Rio de Janeiro: AXCEL, 2003.

> KIRNER, Claudio; SISCUOTTO, Robson. Realidade Virtual e Aumentada: Conceitos, Projeto e Aplicações. Sociedade Brasileira de Computação, Porto Alegre, 2007. 


\section{Lavaipe: Arte Interativa A Partir Da Realidade Virtual}

> KONESKI, Anita. 0 murmúrio na arte contemporânea. In: MAKOWIECK, S.; OLIVEIRA, S. R. R. (Org.). Ensaios em torno da Arte. Chapecó, ARGOS, 2008.

> MELIN, Regina. Performance nas artes visuais. Rio de Janeiro: Jorge Zahar, 2008.

> MONK, Simon. 30 Arduino Projects for the Evil Genius. New York: McGraw-Hill/TAB Electronics, 2010.

> NUNES, Fábio Oliveira. Ctrl+Art+Del: distúrbios em arte e tecnologia. São Paulo: Perspectiva, 2010.

> SCHELL, Jesse. A Arte de Game Design: o livro original. São Paulo: Editora Elsevier, 2011.

> SOUZA E SILVA, Adriana de. Artes, interfaces gráficas e espaços virtuais. ARS, v. 2, n. 4, São Paulo, 2004.

Maria Cristina da Rosa Fonseca da Silva, PPGAV - UDESC

cristinaudesc@gmail.com

Kainan Silvano Fernandes, Estudante do Bacharelado em Artes Visuais - CEART/ UDESC

kainan_fernandes@hotmail.com

Osmar Yang, Estudante do Bacharelado em Artes Visuais

osyang@yahoo.com.br 